\title{
Impact of host ageing on the metastatic phenotype
}

Brian Meehan, Alexander Dombrovsky, Karrie Lau, Tiffany Lai , Nathalie Magnus, Laura Montermini \& Janusz Rak

Montreal Children's Hospital, RI MUHC, McGill University, Montreal, Quebec, Canada

*Correspondence should be sent to: Janusz Rak: Montreal Children's Hospital, Place Toulon, 4060 Ste Catherine West, PT-232 Montreal, Quebec, H3Z 2Z3, Canada; Tel. (514) 412-4400; Fax (514) 412-4331; e-mail: janusz.rak@,mcgill.ca

Abbreviations: LLC - Lewis lung carcinoma; ECIS - electrical cell-substrate impedance sensing; 


\begin{abstract}
Ageing impacts multiple host mechanisms involved in cancer progression. Here we show that poorly metastatic Lewis lung carcinoma (LLC) cells form less bulky metastatic deposits in aged mice ( $>52$ weeks) relative to their young (4-6 weeks) counterparts. Serial selection of LLC cells for increased metastatic capability in either young or old mice led in both cases to exaggerated growth of pulmonary nodules after only 5 cycles of in vivo passage. While the respective metastatic cellular variants established in young (Y-series) or old (O-series) mice exhibited differed in cell morphology and constitutive activity of growth factor receptors, especially phospho-PDGFRa and phospho-EPHA7. These cell lines also exhibited marked differences in their time dependent profiles of cellular impedance (CI), which reflects their physical properties, such as cell shape, adhesion and interactions with substrata. In confluent monolayer culture Yseries cell lines generated high and increasing CI values, while these values remained low and constant in the O-series of cell lines. These observations suggest that the selective pressure of the metastatic microenvironment in young versus old hosts is sufficiently different to results in the enrichment of distinct, age-related metastatic phenotypes of cancer cells. Thus, age could impact therapeutic approaches to metastatic cancers.
\end{abstract}

Keywords: ageing, tumor dissemination, tumor heterogeneity, cellular impedance

\title{
1. Introduction
}


Metastasis represents the culmination of cancer progression. From the practical standpoint this process is often the major constituent in disease intractability, and the ultimate cause of the vast majority of cancer-related deaths (Fidler 2003). While the specific molecular drivers of cancer cell dissemination may be somewhat unique to the particular disease settings (Wu et al. 2012), several general mechanisms of metastasis have also been studied over the past several decades. Some of the main tenets in these investigations include the role of cancer cell phenotype ('seed') and the target organ microenvironment 'soil'(Fidler 2003; Chiang and Massague 2008; Steeg et al. 2011) in completion of the metastatic process ('cascade'). The many determinants of the final outcome include host genetics (Hunter 2006), the role of the immune system and bone marrow derived 'niche' cells (Kaplan et al. 2005), intercellular communication (Peinado et al. 2012), coagulation system activation (Palumbo et al. 2007), as well as the essential involvement of lymphatics (Karnezis et al. 2012) and blood vessel networks in trafficking of metastatic cancer cells (Folkman and Kalluri 2003). These different mechanisms contribute in various ways to one, or more, of the operational steps in the metastatic cascade, either at the point of entry of cancer cells into the vascular or lymphatic space (intravasation), during their survival and passage through the circulation, or at their point of exit (extravasation) and overt growth at distant organ sites (Fidler 2003).

One common thread in these studies is that the various selective pressures exerted upon the heterogeneous cancer cell population at different stages of metastasis result in a selective enrichment of cellular clones endowed with an increased potential to complete the entire dissemination process, and form the bulky and clinically apparent metastatic disease (Fidler 2003). Indeed, Fidler originally demonstrated that such highly metastatic cellular variants can be isolated from poorly metastatic tumor cell populations by sequential tumor cell selection for 
growth as secondary nodules in ectopic organ sites, such as lungs, liver and other tissues (Fidler 1973). This approach, which has since been widely adopted, usually involves either a direct intravascular injection of cancer cells (experimental metastasis), or generation of the primary tumor followed by spontaneous dissemination of tumor cells to their various organ destinations, from which they can be recovered and analysed experimentally. Thus, repeated cycles of isolation, culture and re-inoculation of metastatic cancer cells invariably lead to the establishment of highly metastatic variant cell lines, and represent a compelling example of the interplay between diversity of host factors and organ microenvironments and the heterogeneity of cancer cell populations (Fidler 1973).

These approaches enabled a discovery of several distinctive features associated with the metastatic phenotype, with an understandable emphasis on molecular signatures and effector pathways of cancer cells themselves (Clark et al. 2000; Chiang and Massague 2008). Hiwever, several host-related variables have also been implicated in these metastatic interactions, including inflammation (Spicer et al. 2012), the state of the vasculature (Folkman and Kalluri 2003), or the activation of the coagulation system (Palumbo et al. 2007; Versteeg et al. 2008).

Although cardiovascular medicine provides countless examples of how these particular host facets are affected by the organismal ageing, the role of age is rarely considered in the context of metastasis (Ershler et al. 1983; Balducci and Ershler 2005; Anisimov 2006; Rak et al. 2008). In fact, the vast majority of experimental studies aimed at deciphering the mechanisms of cancer dissemination are, for practical reasons, conducted with mice that are 4-6 weeks old, which corresponds to approximately $8-10 \%$ of the average life expectancy in this particular species. This differs sharply from the age when metastatic cancers reach noticeable prevalence in the 
human population (often past 50\% of the life expectancy) (Balducci and Ershler 2005; Rak et al 2008).

Notably, several types of metastatic human cancers can emerge across the age spectrum (e.g. brain and kidney cancers, lymphoma, acute leukemia), often decades apart in different patients. In those cases, age has a documented impact on the biology and clinical course of the disease for reasons that are presently poorly described (Balducci and Ershler 2005). Moreover, the vascular system (the main conduit of metastasis) undergoes significant changes over the life time (Lusis 2000). Aging also affects bone marrow function (Rauscher et al. 2003), the inflammatory system and mechanisms of angiogenesis (Pili et al. 1994; Rivard et al. 1999; Zhu et al. 2003). We have previously documented impaired growth, neovascularisation and therapeutic responses of experimental tumors in aged mice relative to their young (standard) experimental counterparts, especially in the context of age-related comorbidities, such as atherosclerosis (Klement et al. 2007). We have also documented age-related structural and molecular differences in the vasculature of human tumors at one of their primary sites (kidney) (Meehan et al. 2011). In view of these observations it is reasonable to ask whether ageing affecting the vascular system and other host compartments in a manner that may have a meaningful bearing on the development of the metastatic disease.

Here we show that in the well characterized model system of poorly metastatic Lewis lung carcinoma (LLC) age affects the ability of cancer cells to grow robustly at the metastatic site (lung). We also document that when young or old mice are used for serial selection of LLCderived metastatic variants in vivo, the phenotypes of the resulting cellular subpopulations are not identical. Indeed, while such variants exhibit similar growth kinetics in culture their morphology, growth factor receptor phosphorylation and bio-electric impedance is markedly 
different. While the mechanisms and implications of these observations remain to be understood in a greater detail, this is the first piece of experimental evidence to suggest that age may influence the nature not only of the metastatic process but also of the very metastatic phenotype of cancer cells.

\section{Materials and Methods}

\subsection{Cells and culture conditions.}

Lewis Lung Carcinoma (LLC) cells were purchased from American Type Culture Collection (ATCC, Manassas, VA), and maintained in Dulbecco's Modified Eagle's Medium (DMEM; GIBCO) supplemented with $10 \%$ fetal bovine serum (FBS) and $1 \%$ penicillin-streptomycin (GIBCO). All derivative sublines were maintained under the same conditions with the addition of Gentamycin and Fungizone, and periodically refreshed from frozen stocks. The morphology of all cultured cell lines was documented by phase-contrast microphotography, using Leica DM IRB inverted microscope.

\subsection{Experimental metastasis.}

The syngeneic C56/B16 female mice (Charles River, Sherbrook, QC) were used as tumor recipients, either at a standard young age (4-6 weeks), or upon ageing for 52 weeks, or more (up to 18 months). The mice were injected intravenously (i.v.) into the tail vein with a single cell suspension containing $5 \times 10^{5}$ LLC cells per mouse in $0.2 \mathrm{~mL}$ of phosphate buffered saline (PBS). In some experiments, this cell number was reduced to $10^{5}$ per inoculum due to the 
excessive metastatic burden that accompanied serial selection. The mice were sacrificed 17-19 days post-injection, and their lungs were excised fixed in formalin and analysed. For this purpose, lungs were filled with $1 \%$ paraformaldehyde, fixed, photographed and inspected for metastasis. Metastatic nodules were counted and their sizes measured individually, under high power dissecting microscope as indicated (Fig, 1), followed by volume calculation, according to the standard formula for the ellipsoid: $\mathrm{V}=\mathrm{ax} \mathrm{b}^{2} / 2$, where " $\mathrm{V}$ " is the volume of the nodule, a" is a larger perpendicular diameter and " $b$ " is a smaller diameter (Rak et al. 1995a).

\subsection{Age-specific selection of metastatic variants.}

The principles of the protocol developed by Fidler (Fidler 1973) were used to establish lung metastasizing variants of LLC cells in young or old mice. Briefly, mice were injected with LLC cells i.v., sacrificed as above, and the largest macroscopic nodules from separate lobes were individually established in culture. To do so, nodules were aseptically excised, minced with scalpel blades and cells dispersed using Collagenase/Dispase (Roche) solution, at a concentration of $1 \mathrm{mg} / \mathrm{mL}$ in $\mathrm{PBS}$, at $37^{\circ} \mathrm{C}$ for 1 hour. After extensive washing cell pellets were re-suspended in DMEM supplemented with 10\% FBS and antibiotics (Pen/Strep, Fungizone and Gentamicin) and cultured for 2-3 passages. After freezing individual cell lines derived from young (Y-series), or old mice (O-series) were pooled and re-injected i.v. to secondary recipients. We observed a progressive increase in metastatic burden in each passage, such that the protocol was stopped after 5 cycles (as in Fig. 2). 


\subsection{Gene expression analysis.}

To analyze the candidate gene expression in various parental and metastatic cell lines, we followed the standard mRNA extraction protocol. Cells were grown on $10 \mathrm{~mm}$ culture dishes to $80 \%$ confluency, followed by extraction with $1 \mathrm{~mL}$ of TRIZOL reagent (Invitrogen) according to manufacturer's recommendation. The RNA precipitate was briefly air-dried, dissolved and quantified using a Nano Drop ND-1000 spectrophotometer (Thermo Scientific, Fisher, Canada). Reverse-transcription into cDNA and amplification was carried out using a one-step PCR kit (QIAGEN, Mississauga, ON) with $0.5 \mu \mathrm{g}$ of RNA at $50^{\circ} \mathrm{C}$ for 30 minutes, followed by $95^{\circ} \mathrm{C}$ for 15 minutes. We used the previously validated amplification protocols ((Magnus et al. 2010) and data not shown), which included 30 cycles each involving heating the samples to $94^{\circ} \mathrm{C}, 53^{\circ} \mathrm{C}$ and $72^{\circ} \mathrm{C}$ for $1 \mathrm{~min}$, at each temperature. We also used validated primers including: $\mathrm{TF}$ (TGCTTCTCGACCACAGACAC and TAAAAACTTTGGGGCGTTTG), PAR-1 (CTCCTCA AGGAGCAGACCAC and AGACCG TGGAAACGATCAAC), PAR-2 (TCTCTGCACCAAT CACAAGC and CTTAGCCTTCTT GCCAGGTG), FVII (TCCAGGGACCTCTAGGGACT and CCTCCGTTCTGACATGGATT), TFPI (AATCAACGGCAAACTGACCAACCC and TCGGGAACAAGGCTAAGCAACAGA), TFPI-2 (AAATCTAGACAGGCGTACAGAG AACCACA and AAACTCGAGTGCTT AAGAAAGATGCTTCC), PAI-1 (CTGCTAC CCGAAGgtTCTG and GGAAGCAACA GGAGCATGC), RhoC (GCTGGGCAAGAAGA CTACG and CCTTCCTCAGATCGAACCG), WISP-1 (CGTGGAGCAACGGTATGAG and GAGAGTGAAGTTCGTGGCC), MMP2 (CCTTAAAAGTATGGAGCGACGTCA and AGC GTTCCCATACTTTACGCG), MMP9 (ACCCTGTGTGTTCCCGTTCAT and GATACTGGA TGCCGTCTATGTCGT), COL1A1 (GA CGCCATCAAGGTCTACTG and ACGGGAATC CATCGGTCA), CyclinD1 (GAGgt TCCTGTTCACAATACCTCA and AGACCGCCCA 
CCTGCC), c-Myc (AAGCTGGTCTCGGAGAAGCTG and GGTTTGCCTCTTCTCCACAG A), VEGF-A (TGGCTTTAC TGCTGTACCTC and ACTCCAGGGCTTCATCGTTA), GAPDH (AACTTTGGCATtGTGG AAGG and ACACATTGGGGGTAGGAACA).

\subsection{Phospho-receptor tyrosine kinase (RTK) array.}

The activation state of various regulatory pathways in LLC-derived cellular populations was assayed using the Mouse Phospho Receptor Tyrosine Kinase Array (R\&D Systems, Minneapolis, MN) containing phospho-specific antibodies against 39 mouse RTKs. Cells were plated at $6 \times 10^{5} /$ well to result in confluent cultures in 6-well cluster plates, and 24 hours later cultures were starved in serum free DMEM for 18 hours. The cells were subsequently fed with DMEM containing $10 \%$ FBS for $36 \mathrm{hrs}$, washed with PBS (1X) and the lysates were collected following the manufacturing protocol. Briefly, $250 \mu \mathrm{l}$ of the lysis buffer containing protease inhibitor (Roche) and phosphatase inhibitor cocktail 1:100 (Sigma), were added to each well. The lysates were incubated for 30 minutes at $4^{\circ} \mathrm{C}$ on a rocking platform, collected, centrifuged for 5 minutes at $14,000 \mathrm{x} \mathrm{g}$ and stored at $-80^{\circ} \mathrm{C}$ until used. Following Bradford quantification protein samples were incubated with arrays membranes according to the supplier's recommendations, and the signal was quantified by standard densitometry. The optical density was normalized to the internal control of each membrane, and calculated as a fraction of the strongest sample-related signal (PDGFRa). The results of 2 independent experiments involving all cell lines, and 3 rounds of hybridization assays were combined and plotted as indicated. 


\subsection{Growth assays.}

Cultured cells were harvested and their numbers assessed over several days after plating, using the MTS assay, as described earlier (Rak et al. 1995b). Our initial analysis conducted at a wide range of cell densities and serum concentrations revealed relatively similar growth patterns between all cell lines, especially in sparse cultures, with some differences in dense cultures (data not shown). Therefore, further experiments were conducted at high cell density, and in the serum containing medium (10\% FBS). Briefly, the cells were plated in triplicate at $8 \times 10^{5} /$ well in 6 well cluster plates, starved in serum free DMEM for 24 hours and subsequently fed with DMEM containing 10\% FBS (time 0). At the time intervals indicated cells were either harvested and counted using a hemocytometer and trypan blue, to distinguish between viable and non-viable cells (for adherent cells the viability was always above 90\%). Alternatively the cell numbers were assayed using the MTS kit (Promega Co, Madison, WI), as recommended by the supplier.

\subsection{Flow cytometry.}

To assess cell cycle distribution of various metastatic cells, LLC sublines were cultured as above, and both adherent and non adherent (floating) cell populations were collected, washed, suspended in PBS, permeabilized with 70\% ethanol, fixed in 1\% paraformaldehyde (PFA) and stained with propidium iodide, as described earlier (Rak et al 1995b). The DNA content analysis was performed using FACScalibur ${ }^{\mathrm{TM}}$ instrument (BD Biosciences, San Jose, CA) and FlowJo software. The results were computed as a \% of cells in G1/Go, M and G2/M phases of the cell cycle. 


\subsection{Impedance measurement (ECIS).}

The Real Time Cell Analyser DP (RTCA, xCELLigence, Roche) platform was used to perform measurements of cellular impedance over time, according to manufacturer's recommendations. Briefly, the cells were plated at high density (as for growth and P-RTK assays) in 16-well cluster plates equipped with the gold electrode. Following starvation for 24 hours and subsequent feeding with DMEM/10\% FBS the cells were left undisturbed in the cell culture incubator, while the impedance (Cell index - CI) was being continuously recorded and plotted by the instrument, as indicated.

\subsection{Data analysis.}

All assays were reproduced at least twice, with similar results. Whenever applicable, the statistical analyses were performed using Student t-test with the $\mathrm{p}<0.05$ value taken as significant.

\subsection{Experiments involving animals.}

The aforementioned experimentation with mice was conducted in accordance with the guidelines of the Canadian Council of Animal Care (CCAC), and while following the Animal Utilization Protocol (AUP) approved by the Faculty Animal Care Committee (FACC) at our Institution. 


\section{Results}

\subsection{Differential growth of lung metastases in young versus old mice.}

We have previously observed that in several transplantable tumor models, including LLC, the age and age-related vascular co-morbidities affect primary tumor growth, angiogenesis, bone marrow cellular reserves and responses to antiangiogenic therapy (Klement et al. 2007). We reasoned that such manifestations of the vascular and organismal ageing may also affect the process of metastasis, which is intimately linked to the blood vessel function and milieu. To examine this possibility we employed the experimental metastasis model, involving generation of lung nodules upon i.v. injection of the well characterized, transplantable mouse LLC tumor cell line, in immunocompetent and syngeneic $\mathrm{C} 57 \mathrm{Bl} / 6$ hosts. We chose to performed these experiments in mice that were at two extremes of the species-specific age spectrum, namely they were either $4-6$ weeks old (designated as "young"), or 52 weeks old, or older (designated as "old"). While the parental LLC cell line is considered to be poorly metastatic, the injection of a large number $\left(5 \times 10^{5}\right)$ of tumor cells resulted in formation of $20-160$ macroscopic lung nodules within 17-21 days of the experiment.

We observed that the numbers of lung nodules were not markedly different between young and old mice, but their size distribution (metastatic burden) was visibly age-dependent, such that smaller nodules were more prevalent in old recipients and larger ones were commonly found in young mice (Fig. 1). To quantify this difference, metastatic lungs were excised, inflated with PFA and fixed at autopsy, followed by their careful viewing under dissecting microscope and measurement of two perpendicular dimension of each accessible surface nodule using morphometry software package (Fig. 1B inset). The volumes of the respective nodules was 
subsequently computed and grouped as either small $\left(<1 \mathrm{~mm}^{3}\right)$, medium sized $\left(1-3 \mathrm{~mm}^{3}\right)$ or large $\left(>3 \mathrm{~mm}^{3}\right)$ metastases. This analysis affirmed that the numbers of large nodules were significantly smaller in old tumor bearing animals and the reverse was true for young mice. Medium sized metastases occurred with similar frequencies in both young and old mice (Fig. 1B). Collectively, these observations suggest that host ageing does not seem to alter the numbers of metastases in lungs (at least under conditions used in these experiments). This may suggest that the initial logging and growth of tumor cells are not significantly affected by age. However, the subsequent expansion of metastases and formation of larger tumors is impaired in old recipients as compared to their young counterparts.

\subsection{Selection for the age-specific metastatic phenotype in vivo.}

Although metastatic nodules in old mice were predominantly small in size (Fig 1) some larger metastases were also observed. This could result from either random variation, or could represent intrinsic differences in metastatic growth capacity of various clones of LCC cells in the biological context of old mice. We reasoned that, if the latter was the case, then it may be possible to overcome the inability of LLC cells to form large metastases in lungs of old mice through their serial in vivo selection for the bulky metastatic phenotype, similarly to the protocol originally described by Fidler (Fidler1973). Thus, LLC cells were injected i.v. to either young or old mice, and larger nodules were individually identified and collected at the experimental endpoint. The cells were dispersed and cultured briefly, whereupon they were re-injected into young or old mice, respectively, to generate metastases again, in an age-specific manner, for a total of 5 cycles (Fig. 2). We observed that in the course of this selection the metastatic disease 
became progressively exacerbated, such that the number of cells inoculated i.v. had to be reduced to $10^{5}$ /mouse to avoid premature morbidity and metastatic overload (data not shown). Nonetheless, in the case of both young and old mice the number of large metastases increased considerably with the consecutive passages and became difficult to accurately enumerate after the fifth cycle (Fig. 2, representative image).

3.3. Metastatic cell lines established in young and old mice exhibit similar candidate gene expression patterns and growth kinetics in vitro.

Out of several metastatic sublines isolated from individual large nodules (as above) 3 cell lines were randomly selected for further analysis from each arm of the selection protocol. These cell lines designated as $\mathrm{Y}$-series (YB2, YC1 and YD1) or O-series (OC3, OD1 and OE1) correspond to the fifth iteration of the metastatic selection in young or old mice, respectively. To assess the possibility of some obvious molecular differences being involved in their phenotype, the cells were screened by semi-quantitative RT-PCR for the expression of selected candidate genes, previously implicated in metastasis, angiogenesis or age-related vascular perturbations (e.g. thrombosis). Surprisingly, no consistent change in this regard was observed between the Y-and O-series of cell lines (Fig. 3), or between them and parental LLC cells. This includes genes involved in the coagulation pathway, such as tissue factor (TF), TF pathway inhibitor (TFPI), protease activated receptors 1 and 2 (PAR-1/2) activated by coagulation factors, coagulation factor VII (FVII), or plasminogen activator inhibitor 1 (PAI-1). Notable in this regard was the ectopic expression of FVII by all cancer cell lines, a property, which is normally restricted to normal liver cells (Magnus et al. 2010). Similarly, the expression of metastasis-related genes, 
such as RhoC, WISP-1, MMP-2 and MMP-9 (Bergers et al. 2000; Clark et al. 2000; Margalit et al. 2003; Deryugina and Quigley 2006) did not segregate with biological differences between parental LLC, Y-series and O-series of cells. Neither did we observe any major intrinsic alterations in the expression levels of candidate genes regulating cellular proliferation and transformation (c-Myc, Cyclin D1)(Evan and Vousden 2001), or angiogenesis (VEGF-A)( Ferrara2005)(Fig. 3).

The LLC-derived panel of metastatic cell lines was also analysed for growth in culture under exponential and growth restrictive conditions, the latter including serum starvation, and as spheroids. Once again no apparent differences were observed in these assays (data not shown). This analysis was conducted either with individual cell lines, or using their pooled populations, representative of the $\mathrm{Y}$-series $(\mathrm{F} 5 \mathrm{Y})$, or O-series (F5O) of metastatic tumors. When grown under different density conditions, the viability and metabolic activity of LLC, F5Y and F5O cell lines were measured by the MTS assay and found comparable. A trend was observed in the case of F5Y cells to exhibit an increased MTS activity at lower cell density, relative to LLC and F5O cells, but this has not reached statistical significance (Fig 4A). To assess these processes more precisely we performed cell cycle analysis using flow cytometry, which revealed a somewhat more pronounced retention of cells at the G2/M phase under high density culture conditions, and mainly in the case of the metastatic F5Y and F5O cell lines (Fig. 4B, 3 days). Interestingly, small number of viable floating cells could also be recovered from the corresponding culture supernatants, and of those, F5O cells exhibited a distinct cell cycle distribution profile, as compared to their LLC and F5Y counterparts (Fig. 3C). Overall, metastatic cells displayed several distinct features, but neither our limited gene expression analysis, nor the aforementioned 
standard growth assays revealed robust differences related to selection for high metastatic burden in mice of different age.

\subsection{Differential morphology and growth factor receptor activation of metastatic LLC variants isolated from old mice.}

While the growth differences between LLC sublines were rather subtle according to standard assays, these cells did exhibited noticeable morphological peculiarities (Fig. 5). In particular, F5O cells (derived from old hosts) contained a subset of giant cells with flat morphology, which was especially obvious under sparse conditions, and no such cells were found in F5Y and LLC cultures.

In search for potential molecular correlates of these changes we screened the activation (phosphorylation) status of growth factor receptors in the respective cell lines using the phosphospecific antibody array (Fig. 6). Indeed, activation of several receptors was detected even under standard sub-confluent culture conditions. The most apparent phosphorylation was observed in the case of the platelet derived growth factor alpha (PDGFRa), macrophage stimulating protein 1 receptor (MSPR/RON), and the related hepatocyte growth factor receptor (HGFR/MET), Gas6

receptor $(\mathrm{AXL})$, epidermal growth factor related receptor 2 (ERBB2), fibroblast growth factor receptor 4 (FGFR4), along with several more discrete changes (e.g. MUSK, EPHA7 and IGF1R). Several receptors show little, or no phosphorylation in this setting, including EGFR, ERBB3, Insulin receptor, EPHA6 and several others (Fig. 6 and data not shown). Interestingly, while the levels of RTK phosphorylation of the LLC cells were somewhat more variable (perhaps indicating a level of cellular heterogeneity), we observed modest, but reproducible differences 
between variant cell lines derived from young (F5Y) or old (F5O) mice. For example, the levels of phospho-PDGFRa (alpha), but not PDGFRb (beta), were significantly lower in F5O cells then in the F5Y cell line, and similar trends were also observed for ERBB2, AXL, DKT and MET receptors, albeit this was not statistically significant. A reverse pattern was found for EphA7, but the constitutive phosphorylation levels of this receptor were rather low in this setting. It should be noted that not only F5O, but also LLC cells expressed lower levels of PDGFRa phosphorylation then their F5Y counterparts (the strongest signal in all assays, Fig. 6). The functional significance of these changes is presently unknown, but they suggest that metastatic selection in hosts of different ages results in tangible, constitutive, morphological and molecular differences between the resulting cellular variants.

\subsection{Differential impedance of metastatic cell lines derived from young and old mice.}

One of the emerging technologies capable of continuous and sensitive measurement of physical properties of various cells is known as electrical cell-substrate impedance sensing (ECIS)(Hong

et al. 2011). ECIS captures cellular features related to the electric conductancy under various conditions. From the biological standpoint these changes could be complex and multifactorial, and are often related to the combination of influences contributed by cell shape, adhesion, migration, and various interactions with the substratum, which in this case contains the embedded electrode (Hong et al. 2011). Using the commercially available ECIS platform (xCELLigence) we compared the changes in impedance (cell index - CI) of LLC, Y-series and O-series of tumor cells in culture (Fig. 7). While, once again, sparse cultures generated relatively similar signals (data not shown), stark differences in impedance were observed when the cells 
were cultured at confluence. Thus, CI of LLC cells has initially increased, but at approximately 60 hours the signal leveled off and subsequently declined. A similar profile was observed in the Y-series of cell lines (and in their pooled population) except that in 2 out 3 cells lines CI continued to gradually increase, or remained at a high stable level after 20-60 hours in culture. In contrast, the O-series of cell lines converged on a profile characterized by the low CI, which remained unchanged during the entire length (100 hours) of the experiments, except for a brief initial peak probably related to cell plating (Fig. 7). Because in the aforementioned cell counting, cell cycle and metabolic activity (MTS) assays (Fig. 4 and data not shown) such dramatic differences were not observed, changes in impedance likely reflect cellular properties other then overt growth or survival. It is of note that these measurements capture the time dependent features of cells under analysis, a property that is not readily accessible in standard MTS, cell cycle and molecular profiling assays. It is possible that the ECIS signal reflect the subtle differences in morphology between the respective LLC sublines (e.g. cell size and adhesion, Fig. 5), and/or the consequences of their growth receptor activation patterns (Fig. 6) Since the ECIS technology measures subtle physical interactions, we suggest it is such differences (of presently unknown cellular and molecular nature) that separate the phenotype of cancer cells selected for metastasis in old mice, relative to their parental and $\mathrm{Y}$-series counterparts.

\section{Discussion}

Our study was motivated by the presently poor understanding of the modulating effects of age on the natural history of human cancers. In this regard only a limited body of prior clinical and experimental studies explored age-related alterations in tumor progression, dissemination and 
therapeutic responses (Ershler, Socinski, and Greene 1983; Ershler et al. 1984;Anisimov et al. 1988; Pili et al. 1994; Rivard et al. 1999; Zhu et al. 2003; Balducci and Ershler 2005; Kaptzan et al. 2006; Anisimov2006; Leibovici et al. 2009). This includes our own efforts aiming at a better understanding of the role vascular system may play in these events (Klement et al. 2007; Rak, et al. 2008; Meehan et al. 2011). While in many instances ageing leads to a less aggressive course of experimental cancers (Klement et al. 2007; Leibovici et al. 2009), elegant studies of McCullough and colleagues have demonstrated that the microenvironment of young (but not old) rodent liver may impose a growth suppression and differentiation program on transplantable hepatoma cells (McCullough et al. 1994; McCullough et al. 1997; McCullough et al. 1998). This is reminiscent of the less aggressive course of certain types of human malignancies, such as acute myelocytic leukemia (AML), or glioblastoma (GBM) in younger patients (Balducci and Ershler 2005).

In this context, the impact of ageing on the pathogenesis of the metastatic disease is relatively less studied. In this context it remains unclear whether and how the choice of therapeutic options, likelihood of drug resistance, development of biomarkers, and the overall biology of dissemination may be affected by patient age (and which aspects thereof) in various cancer settings (Balducci and Ershler 2005).

Metastatic cancers are thought to evolve through reciprocal interactions between cancer cells and their surroundings (i.e. the 'seed and soil' of the process) (Fidler2003). This is taken to mean that tumors with a metastatic potential may condition distant organ sites as niches for the secondary growth, a process that involves recruitment of bone barrow cells and other mechanisms (Kaplan et al. Lyden 2005; Peinado et al. 2012). On the other hand, cancer cells are thought to acquire metastatic phenotype as a result of selective pressures operative in various target organs, effects 
that favor clones harbouring certain cellular properties (and mutations) over the other (Fidler 2003; Chiang and Massague 2008; Wu et al. 2012). Since the molecular make up of morphologically similar tumors is not identical in various age groups (Faury et al. 2007), it is tempting to ask whether (and to what extent) ageing processes also intersect with mechanisms of mutational variability and host-dependent selection of metastatic cancer cell variants (Nowell 1976).

In this regard our study focuses on a relatively simple case of experimental metastasis, and in so doing brings forward several novel observations. Thus, we documented that the growth of the same population of cancer cells (LLC), as lung metastases, is markedly influenced by the age of the host. This mechanism affects the burden of metastatic disease but not necessarily the number of metastatic nodules, each endowed with a growth potential.

The restriction on the formation of large lung nodules in old mice is consistent with our prior observations pertaining to primary tumors (Klement et al. 2007). It is possible that the nature of this effect is related to the previously described age-related impairment in the onset of tumor angiogenesis (Pili et al. 1994; Zhu et al. 2003; Klement et al. 2007; Leibovici et al. 2009) occurring in the lung, as suggested by the restriction of the nodule sizes to the presumed preangiogenic threshold of less than $1 \mathrm{~mm}^{3}$ in diameter (Folkman and Kalluri 2003). However, we also observed that individual metastases do acquire larger sizes even in old mice, whereby they exhibit an intrinsic ability to overcome this restriction, whatever its nature.

We reasoned that the regulation of seeding and growth of metastatic cells in distant organs is a function of the interplay between their intrinsic properties and the host microenvironment. The specific (and variable) features of such a selective milieu may implicitly favour certain cellular 
variants over the others, as evidenced by the phenomenon of organ specific metastasis (Chiang and Massague 2008). Therefore, it is reasonable to ask whether, by analogy, the same or different subsets of cancer cells become metastatic to, and capable of aggressive growth in, the lung in the different tissue microenvironments that separate the young versus old hosts. We approached this question by adopting the selection protocol designed originally by Fidler (Fidler 1973), and embarked on isolation and characterization of the putative age-specific metastatic phenotypes, as defined as their ability to form large lung nodules. To our knowledge this is the first experimental attempt of this kind published in the literature.

As expected, we observed an increase in the metastatic burden following the consecutive cycles of intravascular inoculation and culture of large nodules. Surprisingly, the resulting cell lines expressed similar patterns of candidate metastasis-related genes. For example, effectors of the coagulation system were not changed in metastatic cells, in spite of the sizable body of literature linking coagulation system to exacerbated metastasis (Palumbo et al. 2007). It is possible that the parental LLC cell line, which expresses ample amounts of TF and other effectors, has already passed the threshold of pro-coagulant activity required for metastasis or that coagulation effectors play a role in entrapment of cancer cells in the lung, but not in their subsequent growth. Similarly, the levels of VEGF and other candidate genes were not markedly different between LLC, Y-series and O-series of cell lines, possibly for similar reasons.

However, we observed that the cells selected in different host did acquire subtle changes in growth, morphology and signalling patterns. For example, the metastatic cells isolated from old mice exhibited large sizes anf flat morphology in culture, features that were not apparent in cultures of parental LLC cells and their variants selected in young mice. 
Interestingly, the constitutive activity (phosphorylation) of certain growth factor (RTK) receptors differed between metastatic LLC variants derived from young and old mice. The most prominent and antithetical changes were observed in the case of phosphorylated PDGFRa (but not PDGFRb) and the ephrin receptor EPHB7. These pathways are known to control cell growth and directional motility, respectively (van der Geer et al. 1994; Andrae et al. 2008). Interestingly, EPHA7 is involved in progression of lymphoma, small cell lung cancer and other malignancies (Oricchio and Wendel 2012; Peifer et al. 2012). However, at present, the role of these receptors in age-regulated growth and metastasis is not known and would be of considerable interest for future studies, especially in vivo.

Perhaps one of the most striking and consistent intrinsic differences between metastatic cells selected in old versus young mice lies in their distinct pattern of impedance (CI) in confluent cultures (Fig. 7). Impedance measurements (ECIS) were introduced by Giaever and Keese to characterise interactions of live cells with ionic currents (Giaever and Keese 1984). These effects have since been correlated with a number of cellular parameters, such as cell shape, adhesion, motility, transformation, proliferation, responses to biological agonists and sensitivity to toxic compounds (Wang et al. 2008; Hong et al. 2011; Yang et al. 2011). These correlations, however, are not necessarily universal or obligatory, and reflect mainly physical properties of the respective cell types under specific assay conditions. As such, their molecular and biological underpinnings could vary, and are presently poorly understood (Hong et al. 2011).

In this context it is not surprising that, while we initially employed the ECIS approach to accurately quantify the expected changes in cellular proliferation and shape over time, several other, less sensitive assays did not reveal major alterations in cell growth (MTS, flow 
cytometry). This could mean that ECIS reflects more subtle changes, or ones that time dependent or unrelated to proliferation or cell shape, and are presently difficult to deduce.

It is of note, in this context, that the distinct flat CI curve of the O-series of metastatic cell lines paralleled their large cell morphology and altered activities of aforementioned RTKs. It would be of interest to examine the endogenous levels of the various agonists or isoforms of these receptors (e.g. PDGF-A or soluble EPHA7) that may be produced by the LLC-derived metastatic cell lines, and the consequences of their exogenous addition.

Further clues as to the biological processes that may underlie differential ECIS profiles of Y-and O-series of cell lines would likely come from the extension of our limited gene expression analysis to more complete transcriptome and proteome profiling, which is a part of our larger ongoing efforts. It could be speculated that the plausible molecular mechanisms that translate onto differential ECIS signals may still involve adhesion or extracellular matrix molecules, cytoskeleton or motility factors, in ways that has evaded our initial analysis.

It should be mentioned that the differential metastatic potential of tumor cells in young versus old mice may not necessarily be fully reducible to the intrinsic properties of the aforementioned LLC variants in cell culture. In fact, it is very likely that molecular analysis of lung nodules in vivo may reveal signatures of reciprocal and age-modified interactions between tumor and host cell populations. It is presently unclear what host factors associated with ageing may be involved in such a cross-talk, but our results justify undertaking related studies. It is possible that, as in the case of primary tumors (Pili et al. 1994), the age-related modulation of the metastatic growth could be controlled by altered endothelial cell responses (Zhu et al. 2003; Stampfli et al. 2010), bone marrow derived regulatory niche cells (BMDCs), innate immunity (Kaplan et al. 2005; 
Klement et al. 2007), deregulated host coagulation system (Emmerechts et al. 2012), or other factors still to be identified. In this regard host age has been demonstrated to influence tumor growth, angiogenesis and the profile of responsiveness of transplantable cancers to a wide spectrum of therapeutic agents, including chemotherapy, immunotherapy and anti-angiogenics (TNP-470) (Kaptzan et al. 2006; Anisimov 2006; Klement et al. 2007; Leibovici et al. 2009).

Overall, our study provides the first glimpse into the impact of ageing on the metastatic phenotype in simple experimental settings and paves way to more detailed and molecular analyses of these relationships, and their extension to the human context. Naturally, ageing processes are complex and may proceed along diverse (individual) trajectories resulting in a spectrum of effects on metastatic dissemination. We believe that this is an important and underdeveloped area of investigation. Inasmuch as histologically similar, adult and pediatric malignancies are molecularly different (Faury et al. 2007), so too could be the biology and therapeutic dimensions of the disseminated disease. This is important, as present preclinical drug development efforts, while mainly directed at disseminated cancers, rarely (if ever) use aged mice as model systems (Francia et al. 2011). We postulate that aging may be worthy of greater consideration in both experimental settings and in the clinic.

Acknowledgements. This work was supported by operating grants to J.R. from the Canadian Cancer Society Research Institute (CCSRI) Innovation initiative. The infrastructure support was provided by Fonds de recherche en santé du Quebec (FRSQ). J.R. is the Jack Cole Chair in Pediatric Hematology/Oncology at McGill University. NM is a recipient of the FRSQ doctoral 
studentship We are indebted to our families and colleagues for their unending support and feedback.

Conflict of Interest. Authors declare no conflict of interest 
Figure legends.

Figure 1. Differential growth of lung metastases in young and old mice. A. Experimental metastasis model based on i.v. injection of low metastatic LLC cell line in young and old mice. B. Preferential occurrence of large metastases in young tumor recipients. Tumor nodules on the surface of lungs in young and old mice were measured morphometrically under high power dissecting microscope, as shown in the inset. The numbers of nodules in different designated size ranges was calculated and plotted as mean $\pm \mathrm{SD}$ ( $\mathrm{p}$ values as indicated).

Figure 2. Selection for highly metastatic LLC variants capable of forming large lung nodules in young and old mice. Mice at the two age extremes (4-6 weeks old and over 52 weeks old) were used as i.v. recipients of the same poorly metastatic LLC cell line. After 17-19 days large lung nodules were individually isolated, cultured and re-injected into secondary recipients for a total of 5 cycles. There was an apparent increase in number of large nodules in both young and old mice during this selection process (representative images, see Methods) and LLC sublines selected in young mice was designated as $\mathrm{Y}$-series to distinguish them from the O-series selected in old mice.

Figure 3. Expression of genes related to metastasis, angiogenesis and tumor aggressiveness in metastatic variants selected in young and old mice. Two sets of three different cultured sublines of LLC subjected to 5 cycles of selection for highly metastatic phenotype in either young (YB1, 
YC1, YD1) or old mice (OC3, OD1, OE1) were screened by semi-quantitative RT-PCT for the expression of genes related to metastasis. This included the elements of the coagulation pathway (TF, PAR-1, PAR-2, FVII, TFPI, PAI-1) effectors of the invasive phenotype (MMP2, MMP9), genes associated with the metastatic phenotype (RhoC, WISP-1), angiogenesis (VEGF) or cellular proliferation and aggressiveness (c-Myc, cyclin D1). No consistent association of these effectors with the Y-series or O-series of cell lines was observed.

Figure 4. In vitro growth properties of metastatic cell lines derived from young or old mice. Three different cell lines from each arm of the selection protocol (as in Figs. 2 and 3) were pooled to generate F5Y (YB2, YC1, YD1) and F5O (OC3, OD1, OE1) cell lines. A. MTS assay to determine viability and metabolic activity of LLC-derived cell lines grown at different densities and tested after 2 or 3 days in culture. In spite of a trend for F5Y cells to exhibit stronger MTS signal at lower densities the results are not statistically significant (NS; $p<0.05)$; B. Cell cycle profile of adherent LLC, F5Y and F5O cells in confluent culture after 48 and 70 hours of incubation. After longer culture both metastatic variants exhibit greater G2/M cell content then LLC cells. C. Cell cycle distribution of floating cells recovered from cultures analysed in panel B. There was a notable difference between F5O cells and its counterparts in terms of increase of G1/G0 and G2/M cells after 48 hours and increase in S phase cells after 70 hours.

Figure 5. Morphology of cultured LLC cells and their metastatic variants. The microphotographs depict LLC parental cells and their derived Y-series (F5Y) and O-series (F5O) 
of metastatic variants (pooled populations) derived through passage in either young or old mice, respectively. While the LLC and F5Y cells were relatively similar, F5O cell population contains giant cells with flat morphology (arrows). These cells remain present after the cultures reach confluence on day 3 (magnification: 400X).

Figure 6. Expression of phosphorylated receptors by parental and metastatic LLC sublines. AC. Antibody microarray detection of phospho-RTKs in LLC cells and their sublines derived from lung metastases in young (F5Y), or old (F5O) mice. The images depict one of 3 independently probed membranes and do not capture variability between different runs, or normalization for the background. The coordinates for the specific spots are as follows: A1-2, 23-24 - reference (positive control); B1-2- EGFR; B3-4 - ERBB2; B5-6 - ERBB3; B7-8 - ERBB4; B9-10 FGFR2 (IIIc); B11-12 - FGFR3; B13-14 - FGFR4; B15-16 - Insulin R; B17-18 - IGF1-R; B1920 - AXL; B21-22 - DTK; B23-24 - MER; C1-2- HGFR/MET; C3-4 - MSPR; C5-6 PDGFRa(alpha); C7-8 - PDGFRb(beta); C9-10 - SCFR; C11-12 - FLT-3; C13-14 - M-CSFR; C15-16 - RET; C17-18 - TIE-1; C19-20 - TIE-2; C21-22 - TRK-A; C23-24 - TRK-B; D1-2TRK-C; D2-4 - VEGFR1; D5-6 - VEGFR2; D7-8 - VEGFR3; D9-10 - MUSK; D11-12 EPHA1; D13-14 - EPHA2; D15-16 - EPHA3; D17-18 - EPHA6; D19-20 - EPHA7; D21-22 EPHA8; D23-24 - EPHB1; E1-2- EPHB2; E2-4 - EPHB4; E5-6 - EPHB6; E7-8 - negative control (PBS); F1-2 - reference spots; D. Densitometry of the RTK signal normalized to controls and expressed as a fraction of the strongest sample signal (F5Y-PDGFRa). Only measurable signals were quantified and plotted. The negative values for EGFR are a result of low expression if this receptor and numerical normalization to the background. The differences in intensity were 
compared using t-test anmd depicted using following designations: ${ }^{*}-\mathrm{p}<0.05 ; * *-\mathrm{p}<0.005$; NS - insignificant difference.

Figure 7. Distinct pattern of changes in culture impedance of LLC cells and metastatic variants isolated from young and old mice. Over 100 hours of continuous monitoring the impedance (Cell index) of LLC cells rose and dropped. Instead 4 different Y-series cell lines (YB2, YC1, YD1 and pooled) maintained or increased their impedance during that time, whereas the impedance of 4 corresponding O-series cell lines (OC3, OD1, OE1 and pool) remained constant. Thus, impedance distinguishes metastatic cell lines isolated in hosts at different ages. 


\section{References}

Andrae,J., Gallini,R., Betsholtz,C., 2008. Role of platelet-derived growth factors in physiology and medicine. Genes Dev. 22, 1276-1312.

Anisimov,V.N., 2006. Effect of host age on tumor growth rate in rodents. Front Biosci. 11:41222., 412-422.

Anisimov,V.N., Zhukovskaya,N.V., Loktionov,A.S., Vasilyeva,I.A., Kaminskaya,E.V., Vakhtin,Y.B., 1988. Influence of host age on lung colony forming capacity of injected rat rhabdomyosarcoma cells. Cancer Lett. 40, 77-82.

Balducci,L., Ershler,W.B., 2005. Cancer and ageing: a nexus at several levels. Nat.Rev.Cancer 5, 655-662.

Bergers,G., Brekken,R., McMahon,G., Vu,T.H., Itoh,T., Tamaki,K., Tanzawa,K., Thorpe,P., Itohara,S., Werb,Z., Hanahan,D., 2000. Matrix metalloproteinase-9 triggers the angiogenic switch during carcinogenesis. Nat.Cell Biol 2, 737-744.

Chiang,A.C., Massague,J., 2008. Molecular basis of metastasis. N.Engl.J Med. 359, 2814-2823.

Clark,E.A., Golub,T.R., Lander,E.S., Hynes,R.O., 2000. Genomic analysis of metastasis reveals an essential role for RhoC. Nature 406, 532-535.

Deryugina,E.I., Quigley,J.P., 2006. Matrix metalloproteinases and tumor metastasis. Cancer Metastasis Reviews 25, 9-34.

Emmerechts,J., De,V., V, Haenen,S., Loyen,S., van,K.S., Hemmeryckx,B., Vanoirbeek,J.A., Hoet,P.H., Nemery,B., Hoylaerts,M.F., 2012. Thrombogenic changes in young and old mice upon subchronic exposure to air pollution in an urban roadside tunnel. Thromb.Haemost. 108.

Ershler,W.B., Moore,A.L., Shore,H., Gamelli,R.L., 1984. Transfer of age-associated restrained tumor growth in mice by old-to-young bone marrow transplantation. Cancer Research 44, 56775680 .

Ershler,W.B., Socinski,M.A., Greene,C.J., 1983. Bronchogenic cancer, metastases, and aging. J Am.Geriatr.Soc. 31, 673-676.

Evan,G.I., Vousden,K.H., 2001. Proliferation, cell cycle and apoptosis in cancer. Nature 411, 342-348.

Faury,D., Nantel,A., Dunn,S.E., Guiot,M.C., Haque,T., Hauser,P., Garami,M., Bognar,L., Hanzely,Z., Liberski,P.P., Lopez-Aguilar,E., Valera,E.T., Tone,L.G., Carret,A.S., Del Maestro,R.F., Gleave,M., Montes,J.L., Pietsch,T., Albrecht,S., Jabado,N., 2007. Molecular profiling identifies prognostic subgroups of pediatric glioblastoma and shows increased YB-1 expression in tumors. Journal of Clinical Oncology 25, 1196-1208.

Ferrara,N., 2005. VEGF as a therapeutic target in cancer. Oncology 69 Suppl 3, 11-16. 
Fidler,I.J., 1973. Selection of successive cell lines for metastasis. Nature 242, 148-149.

Fidler,I.J., 2003. The pathogenesis of cancer metastasis: the 'seed and soil' hypothesis revisited. Nat.Rev.Cancer 3, 453-458.

Folkman,J., Kalluri,R., 2003. Tumor Angiogenesis. In: Kufe,D.W., Pollock,R.E., Weichselbaum,R.R., Bast Jr.,R.C., Gansler,T.S., Holland,J.F., Frei,E., III, . (Eds.). Cancer Medicine. BC Decker Inc., Hamilton, London, pp. 161-194.

Francia,G., Cruz-Munoz,W., Man,S., Xu,P., Kerbel,R.S., 2011. Mouse models of advanced spontaneous metastasis for experimental therapeutics. Nat.Rev.Cancer. 11, 135-141.

Giaever,I., Keese,C.R., 1984. Monitoring fibroblast behavior in tissue culture with an applied electric field. Proc.Natl.Acad.Sci.U.S.A. 81, 3761-3764.

Hong,J., Kandasamy,K., Marimuthu,M., Choi,C.S., Kim,S., 2011. Electrical cell-substrate impedance sensing as a non-invasive tool for cancer cell study. Analyst. 136, 237-245.

Hunter,K., 2006. Host genetics influence tumour metastasis. Nat.Rev.Cancer 6, 141-146.

Kaplan,R.N., Riba,R.D., Zacharoulis,S., Bramley,A.H., Vincent,L., Costa,C., MacDonald,D.D., Jin,D.K., Shido,K., Kerns,S.A., Zhu,Z., Hicklin,D., Wu,Y., Port,J.L., Altorki,N., Port,E.R., Ruggero,D., Shmelkov,S.V., Jensen,K.K., Rafii,S., Lyden,D., 2005. VEGFR1-positive haematopoietic bone marrow progenitors initiate the pre-metastatic niche. Nature. 438, 820-827.

Kaptzan,T., Skutelsky,E., Itzhaki,O., Sinai,J., Huszar,M., Siegal,A., Ben-Zvi,R., Jossiphov,J., Michowitz,M., Schiby,G., Leibovici,J., 2006. Efficacy of anti-angiogenic treatment of tumors in old versus young mice. Mech.Ageing Dev. 127, 398-409.

Karnezis,T., Shayan,R., Ceasar,C., Roufail,S., Harris,N.C., Ardipradja,K., Zhang,Y.F., Williams,S.P., Farnsworth,R.H., Chai,M.G., Rupasinghe,T., Tull,D., Baldwin,M.E., Sloan,E.K., Fox,S.B., Achen,M.G., Stacker,S.A., 2012. VEGF-D promotes tumor metastasis by regulating prostaglandins produced by the collecting lymphatic endothelium. Cancer Cell in press.

Klement,H., St,C.B., Milsom,C., May,L., Guo,Q., Yu,J.L., Klement,P., Rak,J., 2007. Atherosclerosis and Vascular Aging as Modifiers of Tumor Progression, Angiogenesis, and Responsiveness to Therapy. American Journal Pathology 171, 1342-1351.

Leibovici,J., Itzhaki,O., Kaptzan,T., Skutelsky,E., Sinai,J., Michowitz,M., Asfur,R., Siegal,A., Huszar,M., Schiby,G., 2009. Designing ageing conditions in tumour microenvironment-a new possible modality for cancer treatment. Mech.Ageing Dev. 130, 76-85.

Lusis,A.J., 2000. Atherosclerosis. Nature 407, 233-241.

Magnus,N., Garnier,D., Rak,J., 2010. Oncogenic epidermal growth factor receptor up-regulates multiple elements of the tissue factor signaling pathway in human glioma cells. Blood. 116, 815818. 
Margalit,O., Eisenbach,L., Amariglio,N., Kaminski,N., Harmelin,A., Pfeffer,R., Shohat,M., Rechavi,G., Berger,R., 2003. Overexpression of a set of genes, including WISP-1, common to pulmonary metastases of both mouse D122 Lewis lung carcinoma and B16-F10.9 melanoma cell lines. Br.J Cancer. 89, 314-319.

McCullough,K.D., Coleman,W.B., Ricketts,S.L., Wilson,J.W., Smith,G.J., Grisham,J.W., 1998. Plasticity of the neoplastic phenotype in vivo is regulated by epigenetic factors. Proc.Natl.Acad.Sci.U.S.A. 95, 15333-15338.

McCullough,K.D., Coleman,W.B., Smith,G.J., Grisham,J.W., 1997. Age-dependent induction of hepatic tumor regression by the tissue microenvironment after transplantation of neoplastically transformed rat liver epithelial cells into the liver. Cancer Research 57, 1807-1813.

McCullough,K.D., Coleman,W.B., Smith,G.J., Grishan,J.W., 1994. Age-dependent regulation of the tumorigenic potential of neoplastically transformed rat liver epithelial cells by the liver microenvironment. Cancer Research 54, 3668-3671.

Meehan,B., Appu,S., St,C.B., Rak-Poznanska,K., Klotz,L., Rak,J., 2011. Age-related properties of the tumour vasculature in renal cell carcinoma. BJU.Int. 107, 416-424.

Nowell,P.C., 1976. The clonal evolution of tumor cell populations. Science 194, 23-28.

Oricchio,E., Wendel,H.G., 2012. Mining the cancer genome uncovers therapeutic activity of EphA7 against lymphoma. Cell Cycle. 11, 1076-1080.

Palumbo,J.S., Talmage,K.E., Massari,J.V., La Jeunesse,C.M., Flick,M.J., Kombrinck,K.W., Hu,Z., Barney,K.A., Degen,J.L., 2007. Tumor cell-associated tissue factor and circulating hemostatic factors cooperate to increase metastatic potential through natural killer cell-dependent and-independent mechanisms. Blood 110, 133-141.

Peifer,M., Fernandez-Cuesta,L., Sos,M.L., George,J., Seidel,D., Kasper,L.H., Plenker,D., Leenders,F., Sun,R., Zander,T., Menon,R., Koker,M., Dahmen,I., Muller,C., Di,C., V, Schildhaus,H.U., Altmuller,J., Baessmann,I., Becker,C., de,W.B., Vandesompele,J., Bohm,D., Ansen,S., Gabler,F., Wilkening,I., Heynck,S., Heuckmann,J.M., Lu,X., Carter,S.L., Cibulskis,K., Banerji,S., Getz,G., Park,K.S., Rauh,D., Grutter,C., Fischer,M., Pasqualucci,L., Wright,G., Wainer,Z., Russell,P., Petersen,I., Chen,Y., Stoelben,E., Ludwig,C., Schnabel,P., Hoffmann,H., Muley,T., Brockmann,M., Engel-Riedel,W., $\quad$ Muscarella,L.A., $\quad$ Fazio,V.M., Groen,H., Timens,W., Sietsma,H., Thunnissen,E., Smit,E., Heideman,D.A., Snijders,P.J., Cappuzzo,F., Ligorio,C., Damiani,S., Field,J., Solberg,S., Brustugun,O.T., Lund-Iversen,M., Sanger,J., Clement,J.H., Soltermann,A., Moch,H., Weder,W., Solomon,B., Soria,J.C., Validire,P., Besse,B., Brambilla,E., Brambilla,C., Lantuejoul,S., Lorimier,P., Schneider,P.M., Hallek,M., Pao,W., Meyerson,M., Sage,J., Shendure,J., Schneider,R., Buttner,R., Wolf,J., Nurnberg,P., Perner,S., Heukamp,L.C., Brindle,P.K., Haas,S., Thomas,R.K., 2012. Integrative genome analyses identify key somatic driver mutations of small-cell lung cancer. Nat.Genet. 44, 11041110.

Peinado,H., Aleckovic,M., Lavotshkin,S., Matei,I., Costa-Silva,B., Moreno-Bueno,G., HerguetaRedondo,M., Williams,C., Garcia-Santos,G., Ghajar,C.M., Nitadori-Hoshino,A., Hoffman,C., 
Badal,K., Garcia,B.A., Callahan,M.K., Yuan,J., Martins,V.R., Skog,J., Kaplan,R.N., Brady,M.S., Wolchok,J.D., Chapman,P.B., Kang,Y., Bromberg,J., Lyden,D., 2012. Melanoma exosomes educate bone marrow progenitor cells toward a pro-metastatic phenotype through MET. Nat.Med. 18, 833-891.

Pili,R., Guo,Y., Chang,J., Nakanishi,H., Martin,G.R., Passaniti,A., 1994. Altered angiogenesis underlying age-dependent changes in tumor growth. J.Natl.Cancer Inst. 86, 1303-1314.

Rak,J., Milsom,C., Yu,J., 2008. Vascular determinants of cancer stem cell dormancy--do age and coagulation system play a role? Acta Pathology Microbiology Scandanavia 116, 660-676.

Rak,J., Mitsuhashi,Y., Bayko,L., Filmus,J., Sasazuki,T., Kerbel,R.S., 1995a. Mutant ras oncogenes upregulate VEGF/VPF expression: implications for induction and inhibition of tumor angiogenesis. Cancer Research 55, 4575-4580.

Rak,J., Mitsuhashi,Y., Erdos,V., Huang,S.-N., Filmus,J., Kerbel,R.S., 1995b. Massive programmed cell death in intestinal epithelial cells induced by three-dimensional growth conditions: suppression by expression of a mutant c-H-ras oncogene. Journal of Cell Biology $131,1587-1598$.

Rauscher,F.M., Goldschmidt-Clermont,P.J., Davis,B.H., Wang,T., Gregg,D., Ramaswami,P., Pippen,A.M., Annex,B.H., Dong,C., Taylor,D.A., 2003. Aging, progenitor cell exhaustion, and atherosclerosis. Circulation. 108, 457-463.

Rivard,A., Fabre,J.E., Silver,M., Chen,D., Murohara,T., Kearney,M., Magner,M., Asahara,T., Isner,J.M., 1999. Age-dependent impairment of angiogenesis. Circul. 99, 111-120.

Spicer,J.D., McDonald,B., Cools-Lartigue,J.J., Chow,S.C., Giannias,B., Kubes,P., Ferri,L.E., 2012. Neutrophils Promote Liver Metastasis via Mac-1-Mediated Interactions with Circulating Tumor Cells. Cancer Research 72, 3919-3927.

Stampfli,S.F., Akhmedov,A., Gebhard,C., Lohmann,C., Holy,E.W., Rozenberg,I., Spescha,R., Shi,Y., Luscher,T.F., Tanner,F.C., Camici,G.G., 2010. Aging induces endothelial dysfunction while sparing arterial thrombosis. Arterioscler.Thromb.Vasc.Biol. 30, 1960-1967.

Steeg,P.S., Camphausen,K.A., Smith,Q.R., 2011. Brain metastases as preventive and therapeutic targets. Nat.Rev.Cancer. 11, 352-363.

van der Geer.P., Hunter,T., Lindberg,R.A., 1994. Receptor protein-tyrosine kinases and their signal transduction pathways. Annu.Rev.Cell Biol. 10:251-337., 251-337.

Versteeg,H.H., Schaffner,F., Kerver,M., Petersen,H.H., Ahamed,J., Felding-Habermann,B., Takada,Y., Mueller,B.M., Ruf,W., 2008. Inhibition of tissue factor signaling suppresses tumor growth. Blood 111, 190-199.

Wang,L., Zhu,J., Deng,C., Xing,W.L., Cheng,J., 2008. An automatic and quantitative on-chip cell migration assay using self-assembled monolayers combined with real-time cellular impedance sensing. Lab Chip. 8, 872-878. 
Wu,X., Northcott,P.A., Dubuc,A., Dupuy,A.J., Shih,D.J., Witt,H., Croul,S., Bouffet,E., Fults,D.W., Eberhart,C.G., Garzia,L., Van,M.T., Zagzag,D., Jabado,N., Schwartzentruber,J., Majewski,J., Scheetz,T.E., Pfister,S.M., Korshunov,A., Li,X.N., Scherer,S.W., Cho,Y.J., Akagi,K., MacDonald,T.J., Koster,J., McCabe,M.G., Sarver,A.L., Collins,V.P., Weiss,W.A., Largaespada,D.A., Collier,L.S., Taylor,M.D., 2012. Clonal selection drives genetic divergence of metastatic medulloblastoma. Nature. 482, 529-533.

Yang,L., Arias,L.R., Lane,T.S., Yancey,M.D., Mamouni,J., 2011. Real-time electrical impedance-based measurement to distinguish oral cancer cells and non-cancer oral epithelial cells. Anal.Bioanal.Chem. 399, 1823-1833.

Zhu,W.H., Iurlaro,M., MacIntyre,A., Fogel,E., Nicosia,R.F., 2003. The mouse aorta model: influence of genetic background and aging on bFGF- and VEGF-induced angiogenic sprouting. Angiogenesis. 6, 193-199. 
A
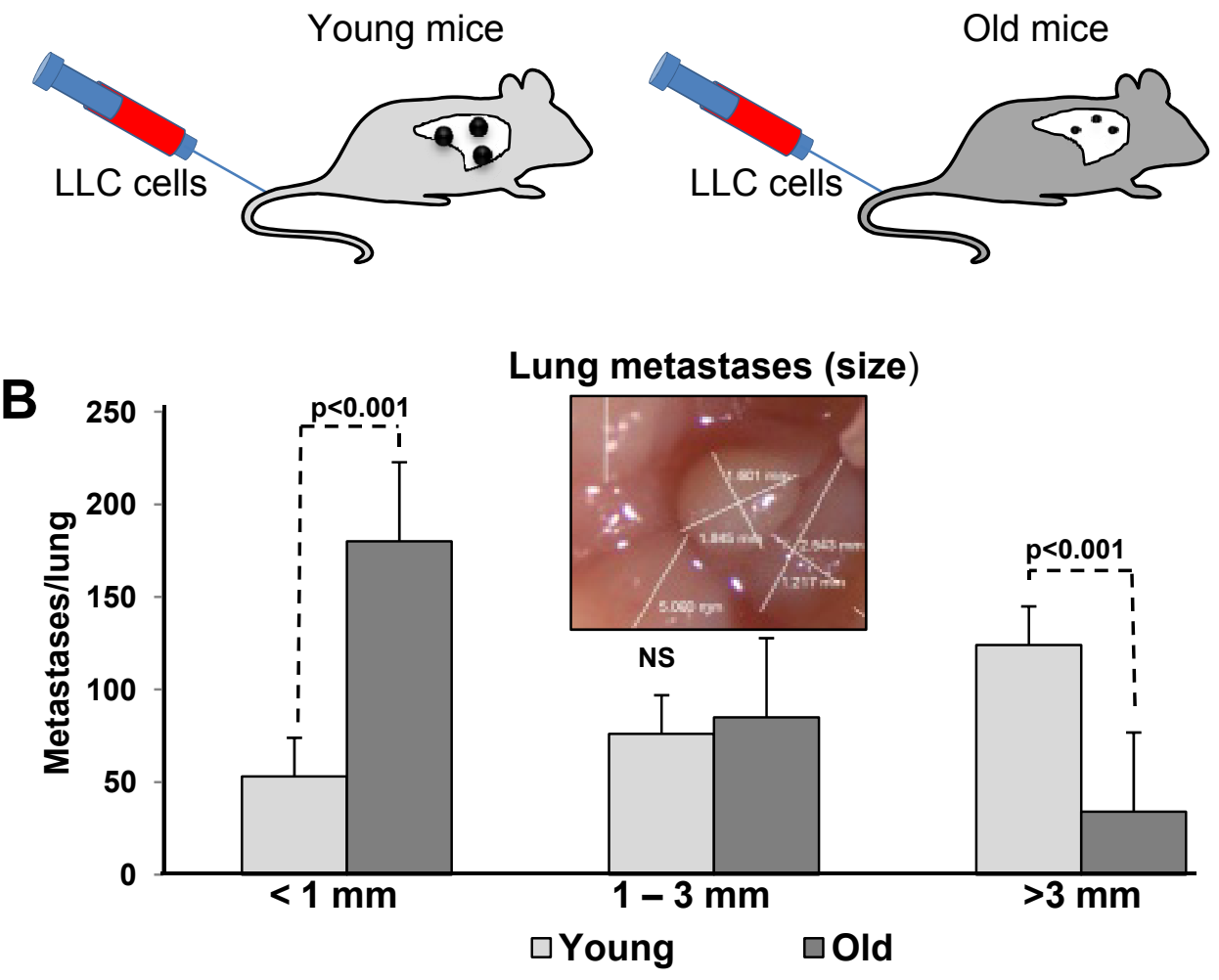

Figure 1. Meehan et al 


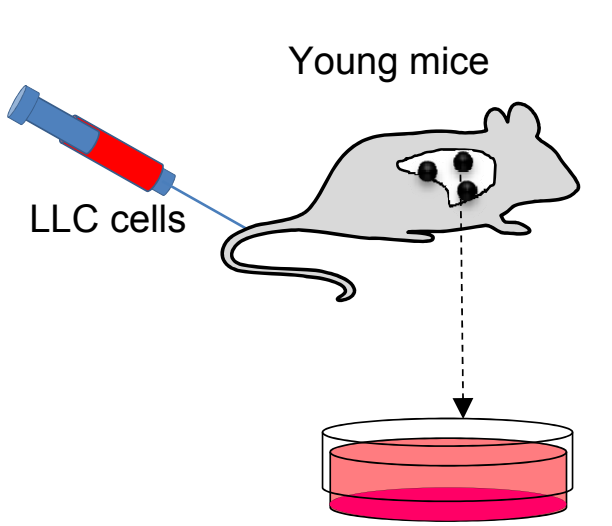

F1Y cells

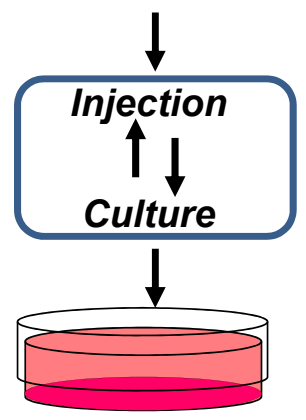

F5Y cells

(YB2, YC1, YD1, pooled)
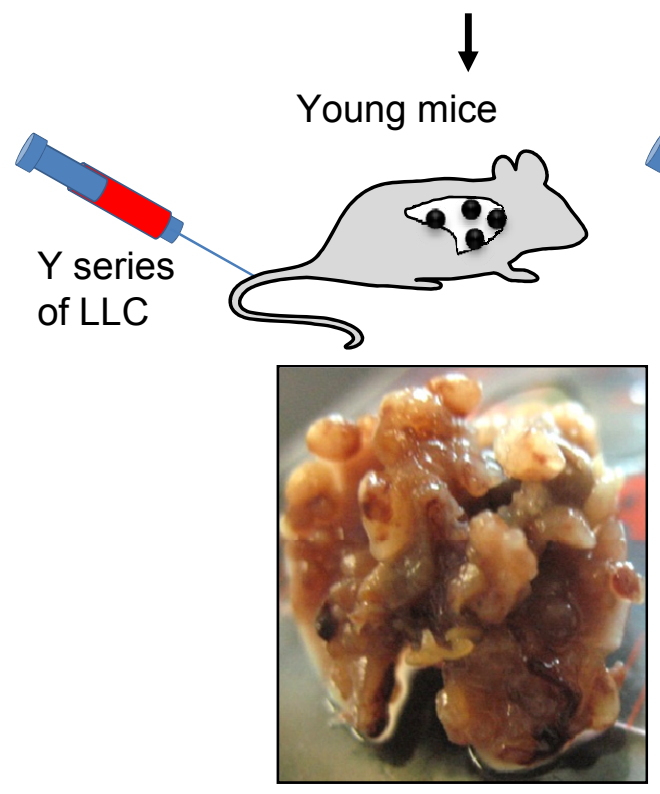

\section{Injection}
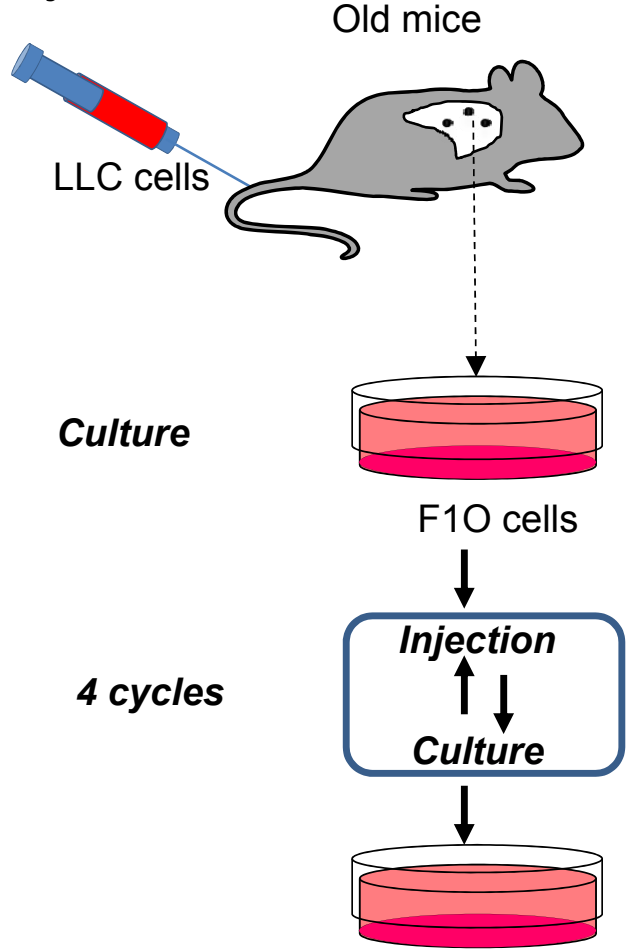

F5O cells

(OC3, OD1, OE1, pooled)

Metastasis assays

Old mice
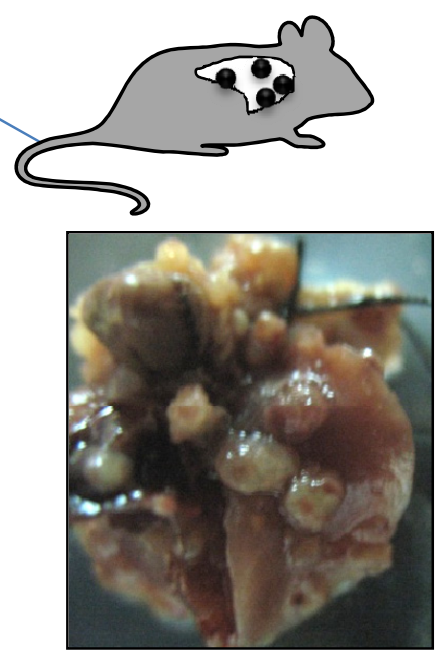

Figure 2. Meehan et al 


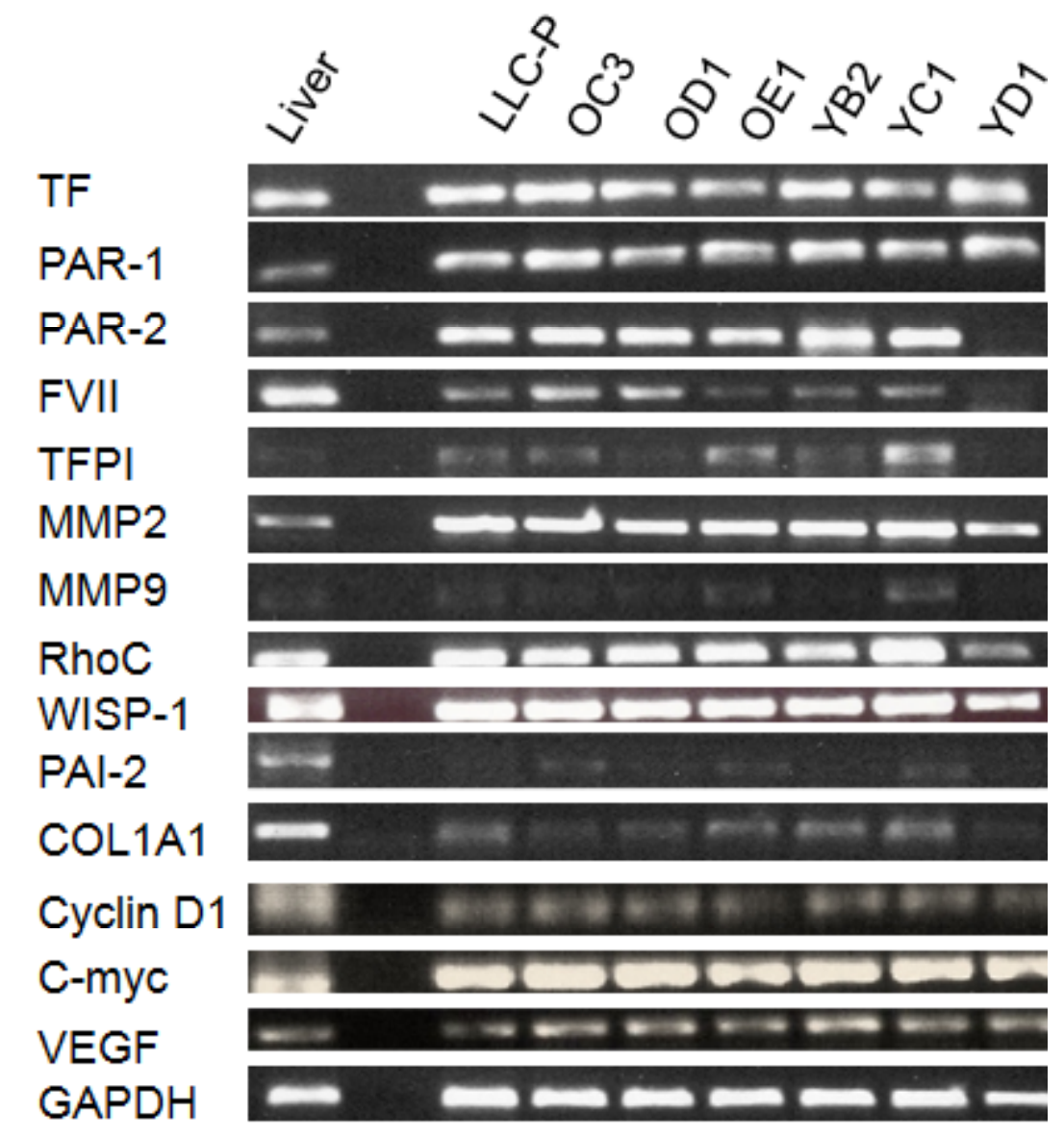

Figure 3. Meehan et al 
A

Adherent cells - viability

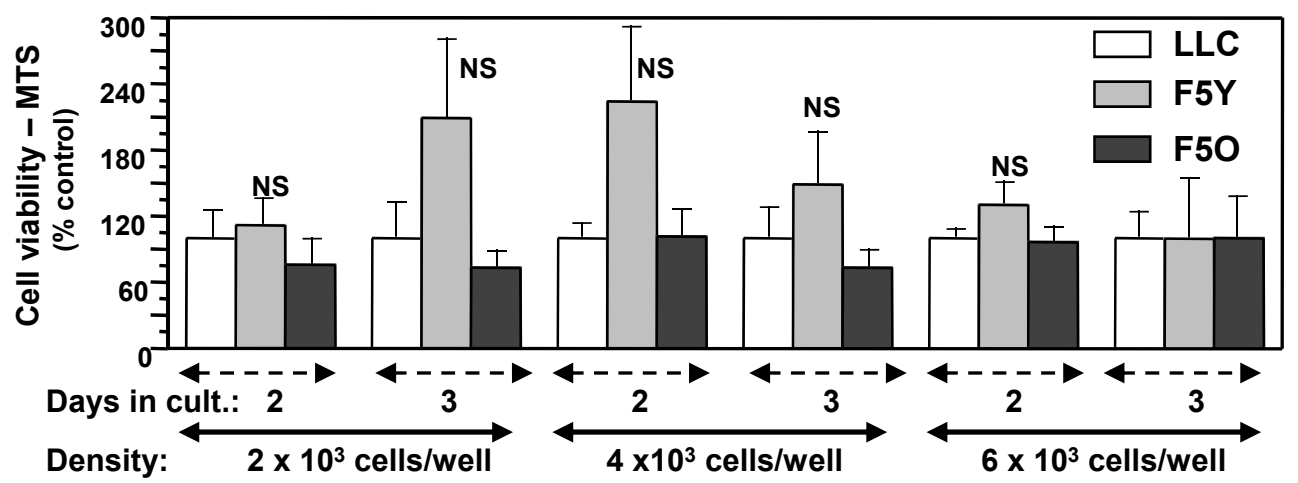

B

Adherent cells - cell cycle
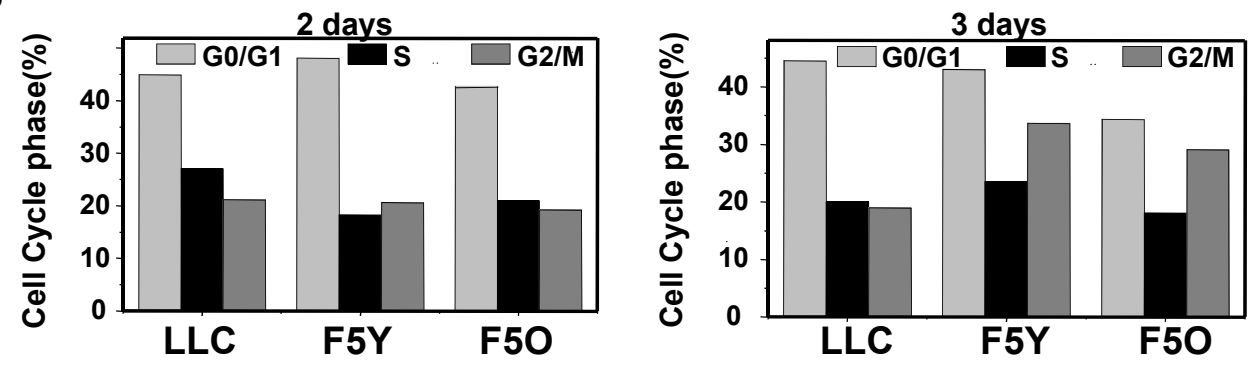

C

Non-adherent - cells cell cycle
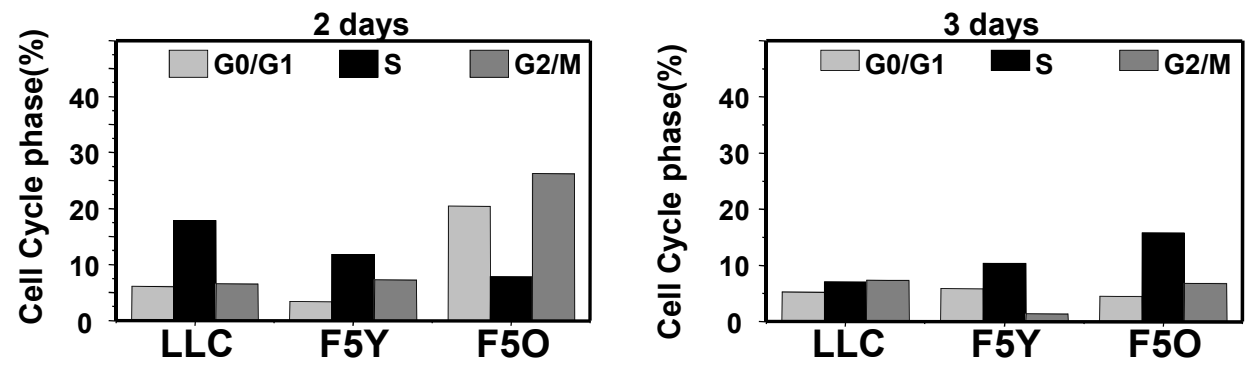

Figure 4. Meehan et al 


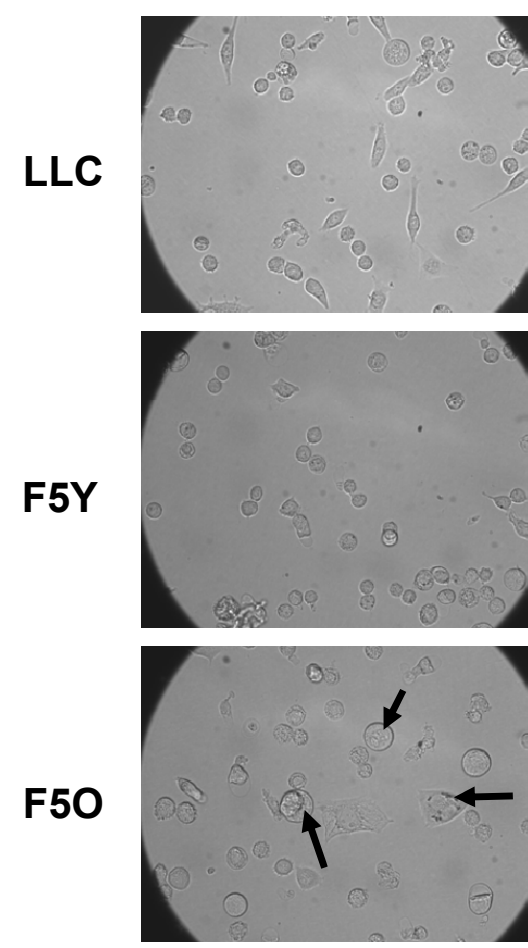

Day 1
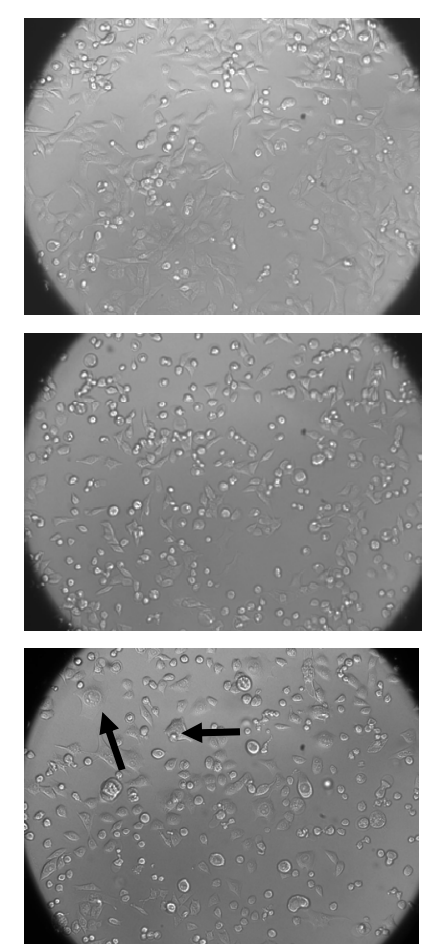

Day 2
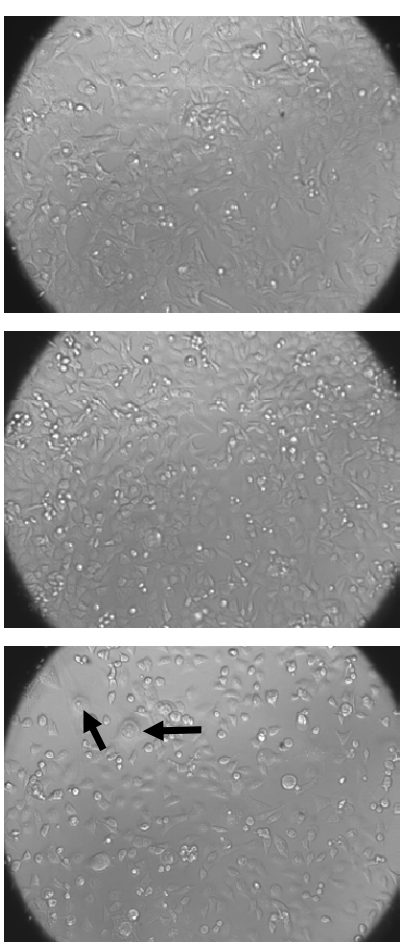

Day 3

Figure 5. Meehan et al 

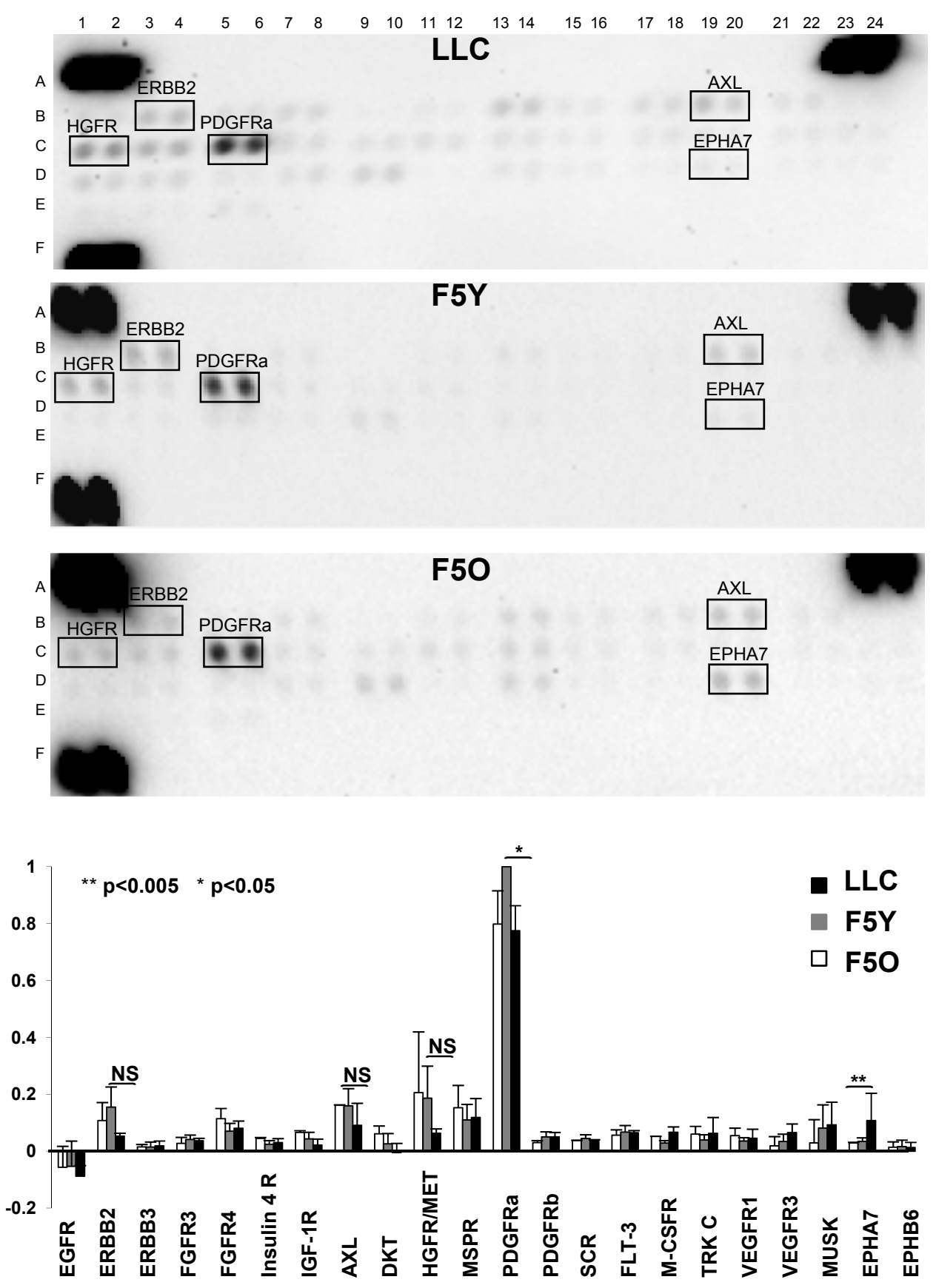

Figure 6. Meehan et al 

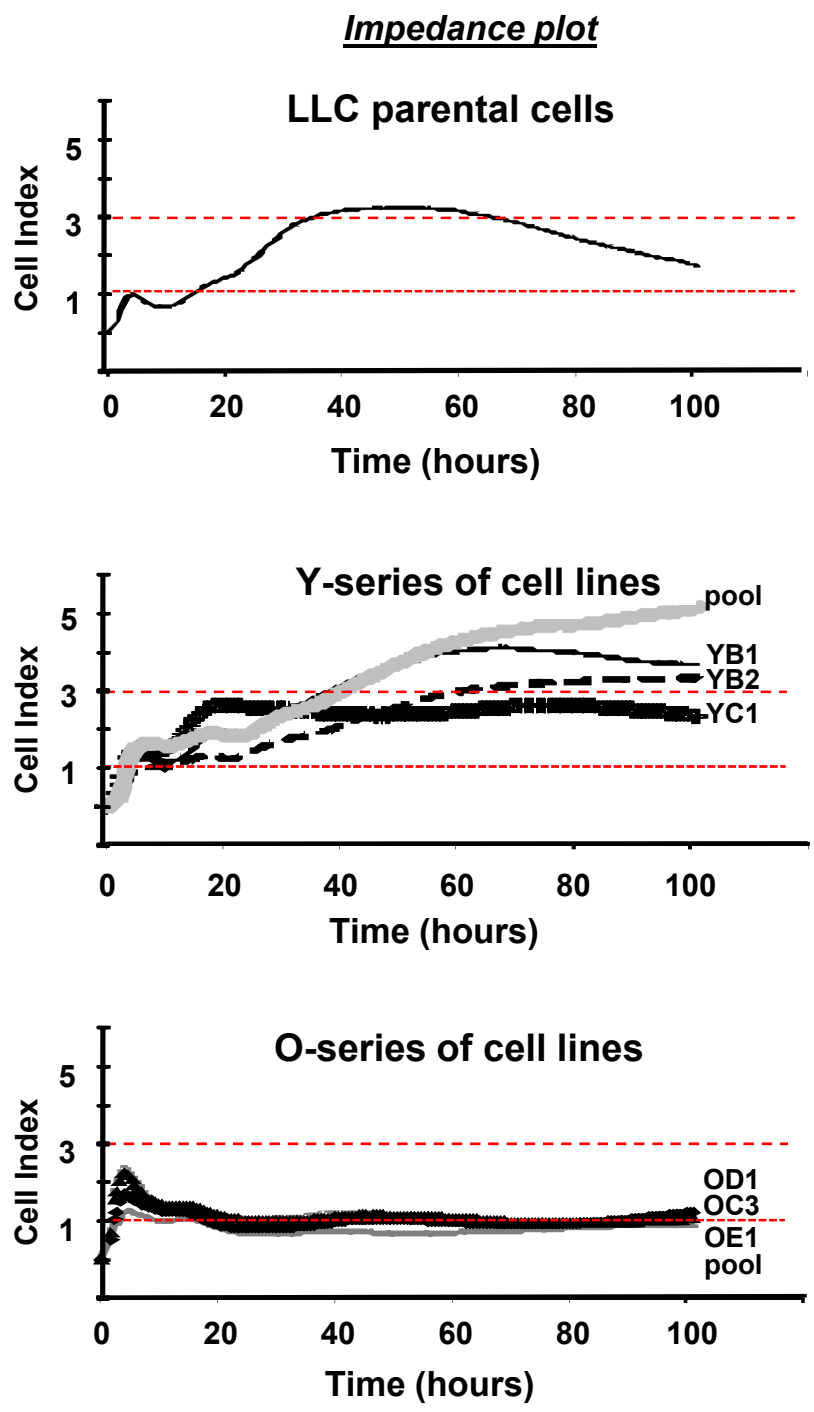

Figure 7. Meehan et al 